\title{
9
}

\section{Assertion, Belief and Disagreement: A Problem for Truth-Relativism}

\author{
Sebastiano Moruzzi
}

\subsection{AN OLD DOCTRINE AND AN OLD CHALLENGE}

Truth-relativism and the attempt to refute truth-relativism have a long tradition. Perhaps, the most famous argument against truth-relativism dates back to Plato's Theaetetus, where Plato tries to show that Protagoras' thesis is self-refuting since it cannot but be false if it is assumed to be true. ${ }^{1}$ However, in this kind of critical discussion, truth-relativism has often been left undistinguished from subjectivism or conceptual relativism. This way of understanding truth-relativism has bound the validity of several arguments offered against it to depend on the acceptance, on the part of the truth-relativist, of doctrines which are not essentially connected to her theory, thus weakening the case against truth-relativism itself. ${ }^{2}$ The discussion about truth-relativism has also suffered from two further problems.

1 Protagoras' Thesis is the so-called Measure Doctrine:

there is nothing which is itself just one thing: nothing which you could rightly call anything or any kind of thing. If you call a thing large, it will reveal itself as small, and if you call it heavy, it is liable to appear as light, and so on with everything, because nothing is anything or any kind of thing. What is is really true, is this: the things of which we naturally say that they 'are', are in process of coming to be, as the result of movement and change and blending with one another. We are wrong when we say they 'are', since nothing ever is, but everything is coming to be. (Theaetetus, 152d-e)

Protagoras' Measure Doctrine is notoriously hard to interpret. It seems fair to say that it is a thesis about the status of perceptual ascriptions: nothing is cold in itself, but only relatively to someone; if we allow to use semantic ascent, one interpretation of this doctrine is that nothing is truly cold in itself, rather the truth of "It is cold" is always relative to someone. Burnyeat has offered an interesting reconstruction of Plato's argument. According to him the conclusion of the argument, which is divided in three steps, is that Protagoras' doctrine is false for everyone, and thus for Protagoras himself (see Burnyeat (1976b); see also Burnyeat (1976a) for an historical reconstruction of how the argument has been understood in later ancient Greek philosophy).

2 Davidson's argument against relativism is based on the idea that the notion of conceptual scheme is untenable (see Davidson (1974); see also Newton-Smith (1982)). For a recent discussion of Davidson's argument see Bilgrami (2002). 
The first problem is that the difficulty faced in properly stating the doctrine has generated the widespread suspicion that the doctrine is essentially unclear, if not incoherent. ${ }^{3}$ The second problem is that truth-relativism has been often understood as a thesis claiming that all sentences ${ }^{4}$ of a language are true relative to a parameter and false relative to another; such a strong formulation of relativism faces the self-refutation charge since it is natural to object that the truth-relativist thesis itself must then be false relative to some parameter. ${ }^{5}$

\subsection{THE REVIVAL OF THE OLD DOCTRINE}

Several proposals in the literature have recently revived truth-relativism trying to make sense of the notion of relative truth and attempting to apply the doctrine for solving different philosophical problems fruitfully. ${ }^{6}$

In this paper I will focus on John MacFarlane's truth-relativist proposal, since he has formulated a very detailed version of truth-relativism arguing that several areas of discourse of English such as future contingents, aesthetic judgements, judgements of taste, epistemic modals, and knowledge attributions can be fruitfully analysed with the help of a truth-relativist semantics (see MacFarlane 2003, 2005a). MacFarlane's formulations of truth-relativism have the merit of dispelling part of the objections which characterize the past literature on relativism. MacFarlane's relativism cannot be accused of unclarity, or even

3 See for example Meiland (1977), Newton-Smith (1982), Siegel's critique to it (Siegel 1986) and Swoyer (1982).

4 Strictly speaking, because of uncontroversial phenomena of context-sensitivity due to, for example, indexical of expressions such as "I", "here" etc..., we should consider utterances of sentences.

5 Of course, the attempt dates back to Plato. Recent discussions of this sort are, for example, Hales (1997) and Bennigson (1999); see also Baghramian (2004, ch. 4). For a recent critique along the traditional line see also Boghossian (2006) (especially ch. 4). In this latter work Boghossian tries to argue against the relativization of facts, however his argument is not forceful against the recent brand of truth-relativism that I will be considering in this paper. First, Boghossian argues against global relativism (i.e. relativism about all the domains) whereas the authors I will be considering have all argued for local relativism. Second, Boghossian seems to assume that truth-relativism is committed to the idea that an utterance of "p" expresses the claim "relatively to X, it is the case that p" (Boghossian (2006), 52), but this is rather what a contextualist would say. Notice also that his regress argument is based on this assumption plus the further assumption that from a global relativist point of view even the fact that "relatively to X, it is the case that p" expresses a claim that needs further relativization - i.e. that claim "relatively to X, it is the case that relatively to X, it is the case that p" which itself expresses a more complex proposition, and so on; the relativist is eventually committed to the idea that the utterance of "p" expresses an infinitary proposition "that we can neither express nor understand" (Boghossian (2006), 56). However, notice that even the standard contextualist is not committed to this further assumption: the context fixes what is said by the utterance and nothing can change this fact; nor is the truth-relativist committed to this idea (even though she could be committed to the idea that what is said is relative to the context of assessment of the utterance; see in this volume Cappelen 2008).

6 See Egan et al. (2004), Egan (2006), Kölbel (2002), Kölbel (2003), Lasersohn (2005), MacFarlane (2003), MacFarlane (2005b), and Richard (2004). 
of using incoherent notions, since he has advanced his proposal providing a detailed compositional semantics and a definition of relative truth. ${ }^{7}$ According to MacFarlane, an appropriate semantics should not only use the relativization to the context in which the act of acceptance is performed (e.g. the context of use of a sentence in the case of assertion), but also to the context in which the truth-value of the sentence is assessed. ${ }^{8}$ The accuracy of acceptance (where acceptance can be a mental act such as a belief or a speech act such as assertion) of a proposition is relative to the assessor's context: the accuracy of my belief that cappuccino tastes better than espresso is relative to the standard of taste of whom is assessing my stance. More precisely:

(Relative Accuracy) An acceptance (rejection) of a proposition on matters of taste $p$ relative to context of use $C_{U}$ is accurate relatively to context of assessment $C_{A}$ if and only if $p$ is true relative to the circumstances $<W_{C_{U}}, S_{C_{A}}>$ where $W_{C_{U}}$ is the world of $C_{U}$ and $S_{C_{A}}$ is the standard of taste of the assessor at $C_{A} \cdot{ }^{9}$

The doctrine of truth-relativism amounts to the claim that, in the language in question, there is at least one assessment-sensitive sentence, i.e. a sentence that, used in a certain context, expresses a proposition which can be correctly assessed in two different ways in two contexts of assessment. ${ }^{10}$

Since the accuracy of acceptance (or rejection) is relative due to the assessmentrelativity of propositions accepted (or rejected) in certain contexts, the norms governing our practice of accepting (and rejecting) need a specific formulation. In fact, the traditional idea of conceiving, for example, truth as the aim of assertion must either be qualified (e.g. to assert "p" is to aim to its truth relatively to the assertor's assessment context) or given up. According to MacFarlane the relativist must choose the latter option. ${ }^{11}$ Instead of conceiving acceptance as aiming at the truth, we must think of acceptance as a commitment to the truth of the proposition accepted. For example, consider the case of assertion: the

7 I will base the exposition of MacFarlane's theory on his latest statement of his theory to be found in MacFarlane (2007).

8 Relativism has to be distinguished from contextualism according to which the same sentence type uttered in two different contexts can have different truth-values since it comes to express two different propositions. Here I leave aside the subtle issues connected to the esoteric (but crucial) distinction between relativism and non-indexical contextualism (see MacFarlane (2007: 26) and, more extensively, MacFarlane (forthcoming)).

9 MacFarlane (2007: 26)

10 Since the notion of acceptance includes both the act of asserting and the act of believing, the existence of an assessment-sensitive belief is also sufficient for the correctness of truth-relativism. Whether or not there is a priority of the linguistic formulation of truth-relativism over the mental formulation or vice versa is an issue that can be left open here.

11 There is no space in this paper for a discussion of reason for or against the "aiming conception" of acceptance (for MacFarlane's discussion see MacFarlane (2005b: 328-37), MacFarlane (2007: $\S 5)$. For critiques to the possibility of making sense of the aiming conception from a relativist standpoint see Evans (1979) and Percival (1994)). For the sake of the argument I will assume MacFarlane's characterization of the norms governing acceptance of a proposition. 
commitment undertaken in asserting a proposition "is commitment to meeting all legitimate challenges to the accuracy of one's assertion, and to withdrawing the assertion (disavowing the commitment) if one cannot do so" (MacFarlane (2007: 28)). The picture, borrowed by the works of Robert Brandom (Brandom 1994), is that acceptance is a move in the game of giving and asking for reasons, a game disciplined by several rules which define the content of the commitment undertaken by each of the moves. In particular, one of these rules dictates that a speaker of a language is committed to justify, if challenged, the proposition she has asserted:

(Relative Assertion 1) In asserting that $\mathrm{p}$ at the context $C_{1}$, one commits oneself to withdrawing the assertion in any future context $C_{2}$, if $\mathrm{p}$ is shown to be untrue relative to context of use $C_{1}$ and context of assessment $C_{2} \cdot{ }^{12}$

(Relative Assertion 2) In asserting that $\mathrm{p}$ at the context $C_{1}$, one commits oneself to justifying the assertion when the assertion is appropriately challenged. To justify the assertion in a context $C_{2}$ is to provide grounds for the truth of $\mathrm{p}$ relative to context of use $C_{1}$ and context of assessment $C_{2}$.

where $C_{2}$ is the context of assessment in which "the assertor is evaluating the putative refutation" (MacFarlane (2005b: 336)). In other words, if the assertor recognizes in a later context that what she asserted is untrue or unjustified, she is committed to retract her assertion on the pain of either being dishonest or of misunderstanding the practice of assertion.

Consider a dispute over the goodness in taste of cappuccino. It is well known that in accounting for the intuition that the dispute is faultless we are faced with a dilemma: either you go with the hard-core objectivist solution holding that one of the disputants is right and the other is wrong with the drawback that it is a mystery why both disputants think they are right and that you are committed to a dubious rampant realist metaphysics of the property of the goodness of taste of cappuccino; or you go with the contextualist holding that both disputants are right since each of them actually expresses something as "cappuccino tastes good (or bad) for me", but the drawback is then that it leaves unexplained why they believe disagreeing (unless an error theory about the semantics of these expressions is postulated for the speakers of the language). ${ }^{13}$

MacFarlane's solution to this puzzle is that since the notion of accuracy is relative to assessment-contexts-i.e. it is a perspectival notion-each of the disputants is right in his own acceptance and in believing that the other is wrong. Given that a necessary condition for disagreement is that not both of the parties can be accurate and that since from both of the contexts of assessment the respective opponent's acceptance comes out as inaccurate, the perspectival

12 MacFarlane also states another principle regarding assertion (MacFarlane (2005b: 336-37)). I will consider only Relative Assertion 1 and 2 because they are relevant for my argument.

13 For a statement of this dilemma see Wright (2006: 38-40) and MacFarlane (2007: 18-21). 
notion of accuracy gives the right result even if the notion of disagreement is itself perspectival:

(Relative Disagreement) Two parties disagree relatively to the context of assessment $\mathrm{C}_{A}$ if (a) there is a proposition that one party accepts and the other rejects, and (b) acceptance and rejection cannot be both accurate (as assessed from $\mathrm{C}_{A}$ )

Does Relative Disagreement give also a sufficient condition for disagreement? MacFarlane himself has highlighted difficulties with regards to the sufficiency condition: given that there are temporal propositions, any acceptance or rejections of them would count as a disagreement (MacFarlane (2007), §3). In Section 8.1 I will argue that the relativist proposal does not take into consideration the point of the disagreement which is to reach an agreement by ratiocinative means (e.g. by means of reasoning or by inspecting the relevant facts). Moreover in Section 8.2 I will argue that ignoring this feature commits the relativist to an ignorance theory for her proposal.

\subsection{THE REVIVAL OF THE OLD CHALLENGE}

Notice that this formulation of truth-relativism evades the classical charge of selfrefutation since it does not imply that every utterance is assessment-sensitive. The truth-relativist is not thus committed to acknowledge that even the truth-relativist thesis is false in respect of some context of assessment. ${ }^{14}$

Still, it might be thought that the truth-relativist is in trouble anyway because of a different version of self-refutation. Suppose that two speakers take opposite stances on a given assessment-sensitive proposition $p$ (one believes that it is true and the other believes that it is false). If the truth-relativist believes that her doctrine can be applied to the case in question-i.e. if she believes that the proposition in question is assessment-sensitive-how can she take a view on this proposition since she believes knowing that the proposition is true relatively to a context of assessment and false relatively to another context of assessment? How can she rationally privilege one of the two contexts once she believes that both can correctly determine the truth-value of the proposition in two incompatible ways? One might think that the relativist should either abstain from any judgement on the relevant proposition or she must give up the idea that the proposition is assessment-sensitive.

${ }_{14}$ Moreover the distinction between object language and metalanguage can be used to deflect the charge of self-refutation arguing that the truth-relativist thesis is formulated in a metalanguage which is "devoid of assessment sensitivity" (MacFarlane (2005b): 338 n. 19) - i.e. a language where no proposition expressed by an utterance of its sentences has a truth-value which varies with the context of assessment. 
Such a conclusion is certainly odd because it seems to imply that the attitude of belief towards a proposition is constrained by whether or not it is believed that the proposition is assessment-sensitive: either (i) it is believed that the proposition is assessment-sensitive without, at the same time, holding any opinion about the proposition in question, or (ii) it is a belief held about the proposition without accepting that the proposition is assessmentsensitive.

In the following I will develop this line of argument in detail. In Section 4 I will introduce a toy example in order to test the truth-relativist proposal in relation to disputes in matter of taste. ${ }^{15}$ In Sections 5, 6, and 7 I will develop three lines of argument which aim to show that acceptance of the truth-relativism in a context of a dispute has problematic consequences. Though I will argue that none of these arguments succeeds in showing that there is a real problem for truth-relativism, these arguments hint at a real problem for the truth-relativist. The problem will be stated in Section 8.

\subsection{A SIMPLE SCENARIO}

Scene 1 Ann: (after sipping cappuccino from a mug) This cappuccino tastes good! Mary: (after tasting the cappuccino from the same mug) No, it is horrible!

Scene 2 Linda, a truth-relativist about taste, joins the party and, listening to the conversation, explains the doctrine of truth-relativism to Ann and Mary. Ann and Mary start discussing about truth-relativism and they are eventually persuaded that truth-relativism is the best explanation of the intuition of faultless disagreement in matters of taste.

\subsection{FIRST ATTEMPT}

Consider now the scenario including Scenes 1 and 2 where Ann and Mary, after disputing about the taste of the cappuccino, are persuaded by Linda to go relativist. In such a scenario they believe that truth-relativism is the true doctrine in matters of taste, in other words they believe they grasp now the correct truth-conditions of their assertions. Let's call the proposition that cappuccino tastes good CAPPUCCINO. Given their new belief, they realize that the accuracy of their acceptance (rejection) of CAPPUCCINO is perspectival:

(Relative Ann) Ann's acceptance of CAPPUCCINO relative to her context of use

$\left(C_{A n n}\right)$ is accurate relative to an assessor context $C_{A}$ if and only if CAPPUCCINO is

15 Kölbel (2002), Lasersohn (2005) and MacFarlane (2007) have argued that truth-relativism can be applied to these disputes. 
true relative to the circumstances $<W_{C_{A n n}}, S_{C_{A n n}}>$ where $W_{C_{U}}$ is the world of $C_{A n n}$ and $S_{C_{A}}$ is the standard of taste of the assessor at $C$

(Relative Mary) Mary's rejection of CAPPUCCINO relative to her context of use $\left(C_{\text {Mary }}\right)$ is accurate relative to an assessor context $C_{A}$ if and only if CAPPUCCINO is true relative to the circumstances $<W_{C_{M a r y}}, S_{C_{A}}>$ where $W_{C_{U}}$ is the world of $C_{M a r y}$ and $S_{C_{A}}$ is the standard of taste of the assessor at $C_{A}$

Ann and Mary believe the truth-relativist doctrine, but can they coherently express that this dispute is faultless while at the same time being engaged in the dispute? Can Ann believe that the dispute between her and Mary is without fault even though she disagrees with Mary? To do this, she has to claim that from the context of assessment $C_{A n n}$, CAPPUCCINO is true and that from the context of assessment $C_{\text {Mary }}$ CAPPUCCINO is false:

(Relative Cappuccino)

- CAPPUCCINO

is true relative to the circumstances $<W_{C_{A n n}}$, $S_{C_{A n n}}>$ where $W_{C_{U}}$ is the world of $C_{A n n}$ and $S_{C_{A n n}}$ is the standard of taste of the assessor at $C_{A n n}$

- CAPpuCCINo

is false relative to the circumstances $<W_{C_{\text {Mary }}}$, $S_{C_{\text {Mary }}}>$ where $W_{C_{U}}$ is the world of $C_{\text {Mary }}$ and $S_{C_{\text {Mary }}}$ is the standard of taste of the assessor at $C_{\text {Mary }}$

Relative Cappuccino is meant to express the thought that there is a genuine case of faultless disagreement: there are two assessment contexts where the same proposition is correctly evaluated with two contradictory semantic values-i.e. as true in one context and as false in the other context.

According to Relative Assertion 1, an assertion of Relative Cappuccino involves a commitment to withdraw the assertion in any future context, if in this context she recognizes that what she asserted is shown untrue. Can Ann and Mary keep the commitment undertaken by asserting and denying in their respective contexts CAPPUCCINO after asserting Relative Cappuccino?

The question is whether, for example, Ann is bound to reject CAPPUCCINO after having asserted Relative Cappuccino. After all, it might be suggested, since Ann accepts Relative Cappuccino she thereby recognizes that Mary has accurately rejected a false proposition from her point of view. And if this is the case, why can't this latter fact count as a piece of conclusive evidence against the commitment undertaken in her previous assertion of CAPPUCCINO?

The careful reader has probably already noted that this reasoning contains two errors: (1) remember that Ann believes that accuracy is perspectival, so she can recognize that Mary has accurately rejected CAPPUCCINO only if, for example, she would be capable of deferring to Mary's standard and so far 
nothing has been said about the possibility of this mechanism of deference; (2) even granting that there is such a mechanism of deference, Relative Assertion 1 dictates to Ann rejecting her assertion of CAPPUCCINO only if CAPPUCCINO is untrue relatively to her standard of taste (selected by her context of assessment), but Ann's actual standard of taste is different from her deferred standard of taste.

In this sense, the charge of pragmatic self-refutation is formally avoided since the belief in the truth-relativist doctrine does not automatically cut the grounds to belief in CAPPUCCINO.

\subsection{SECOND ATTEMPT}

It might be thought that it is incoherent to believe that CAPPUCCINO is assessmentsensitive when we consider a neutral perspective on the matter. Let's suppose that Linda's context of assessment $\left(C_{\text {Linda }}\right)$ is neutral on the dispute between Ann and Mary. ${ }^{16}$

Now, consider Scene 1 only where Ann and Mary still do not know anything about truth-relativism, and let's suppose that Linda is secretly listening to their discussion. If the truth-relativist believes that there is a genuine faultless disagreement between Mary and Ann, she would presumably hold that both are correct and that their assertions are perfectly justified from their respective contexts of assessment. Since Ann and Mary have, from Linda's perspective, a true justified belief it seems natural to say that Linda believes that Ann and Mary are knowledgeable with respect to CAPPUCCINO. ${ }^{17}$ Now, since the truth-relativist's perspective (i.e. Linda's perspective) is neutral with respect to CAPPUCCINO, Linda, the truth-relativist, should be accurate, relative to her context of assessment, in accepting the following propositions:

(1) that Ann knows that CAPPUCCINO

(2) that Mary knows that NOT-CAPPUCCINO ${ }^{18}$

Presumably, the truth-relativist version of factivity would be expressed saying that if a knowledge ascription is true relative to a context of assessment, the embedded sentence is true relative to the same context of assessment. Given the assumption that Linda's acceptance of previous knowledge ascriptions is accurate,

16 The following argument is an adaptation of an argument advanced by Jason Stanley in relation to the truth-relativist analysis of knowledge-ascriptions (see Stanley (2005), 146). Stanley believes that the argument, together with other two arguments, shows that the truth-relativist cannot give any coherent formulation of factivity. My use of the argument is different, since I start from the assumption that there is a natural formulation of factivity for the truth-relativist, but that this formulation of factivity jeopardizes the very idea of a neutral perspective.

17 Putting aside Gettier-style worries.

18 Where, of course, NOT-CAPPUCCINO is the negation of CAPPUCCINO. 
it follows that she is committed to inconsistent propositions. ${ }^{19,20}$ However, it is unclear why the truth-relativist should be committed to the existence of a neutral perspective. On the contrary, assuming bivalence, there are reasons to think the contrary. What does it mean to be neutral about a proposition for a context of assessment? On an epistemic reading of neutrality, to be neutral with respect to a proposition means to be agnostic about the proposition. But since we are dealing here with truth-relativism, the idea is rather that a certain perspective does not commit to the truth or falsity of a certain proposition. However, while the absence of commitment in the epistemic sense amounts to the suspension of judgement, in the alethic case the analogous situation would be that the proposition is neither true nor false. But in this case it is the burden of the objector to justify the claim that for every assessment-sensitive proposition there is a context of assessment in relation to which the proposition is neither true nor false. Why should bivalence fail just because there must be such a neutral perspective?21 The truth-relativist might also add that she could make sense of the idea of a neutral perspective by means of a metalanguage which is devoid of assessment sensitivity.

19 To express more precisely the worry, the proposal amounts to say that acceptance of the relevant knowledge ascriptions is accurate relatively to an assessment context $C_{A}$ just in case:

(3) relatively to the context of assessment $C_{\text {Linda }}$, the proposition that Ann knows that CAPPUCCINO is true relative to the circumstances $<W_{C_{A n n}}, S_{C_{A n n}}>$ where $W_{C_{U}}$ is the world of $C_{A n n}$ and $S_{C_{A n n}}$ is the standard of taste of the assessor at $C_{A n n}$

(4) relatively to the context of assessment $C_{L i n d a}$, the proposition that Mary knows that NOTCAPPUCCINO is true to the circumstances $<W_{C_{\text {Mary }}}, S_{C_{\text {Mary }}}>$ where $W_{C_{U}}$ is the world of $C_{\text {Mary }}$ and $S_{C_{M a r y}}$ is the standard of taste of the assessor at $C_{\text {Mary }}$

- in other words $C_{\text {Linda }}$ features as an idle wheel. The aforementioned truth-conditions amount to the claim that knowledge ascriptions do not inherit assessment-sensitivity from the embedded propositions.

Given now the following rule of factivity of knowledge:

(Relative Factivity)

from relatively to the context of assessment $C_{A}$, the proposition that $x$ knows CAPPUCCINO is true to the circumstances $<W_{C_{x}}, S_{C_{x}}>$ where $W_{C_{U}}$ is the world of $C_{x}$ and $S_{C_{x}}$ is the standard of taste of the assessor at $C_{x}$

infer relatively to the context of assessment $C_{A}$, CAPPUCCINO is true to the circumstances $<W_{C_{x}}, S_{C_{A}}>$ where $W_{C_{U}}$ is the world of $C_{x}$ and $S_{C_{A}}$ is the standard of taste of the assessor at $C_{A}$

Linda's context of assessment is bound to evaluate CAPPUCCINO as both true and false.

20 The previous footnote is symptomatic of the fact that a proposition $p$ is assessment-sensitive if and only if the proposition that is known that $p$ is assessment-sensitive. Suppose that $p$ is true at $C_{1}$ and that not- $p$ is true at $C_{2}$, then $\neg K \neg p$ is true at $C_{1}$ and $\neg K p$ is true at $C_{2}$. If we assume that in both contexts there is a subject who has knowledge of $p$, then $K p$ is assessment-sensitive. The other direction is straightforward: suppose that $K p$ is assessment-sensitive, then two subjects know, respectively, that $p$ and that $\neg p$. By Relative Factivity $p$ is assessment-sensitive (I am indebted for this point to Dan López De Sa).

21 Asssuming here that we are dealing only with propositions for which the truth-relativist analysis clearly does not require the failure of bivalence. 
Finally, the truth-relativist might opt to state the rule of factivity by selecting the standard of assessment of the ascribee of the knowledge claim, hence avoiding that Linda contradicts herself. ${ }^{22}$

\subsection{THIRD ATTEMPT}

It might be argued that CAPPUCCINO cannot be believed because from the point of view of the truth-relativist semantics it is an incomplete entity which cannot be the object of any belief. ${ }^{23}$

A paradigmatic example of an incomplete semantic entity which cannot fulfil the role of a proposition is the propositional function expressed by "I am happy" when this sentence is just written on a blackboard in a class of English language. The sentence expresses something, but it is something we cannot accept or reject. ${ }^{24}$

Consider now the following argument in relation to a scenario which includes Scenes 1 and 2 .

1 (1) According to truth-relativism about matters of taste, it is the case that CAPPUCCINO is true relative to the circumstances $<W_{C_{A n n}}, S_{C_{A n n}}>$ where $W_{C_{A n n}}$ is the world of $C_{A n n}$ and $S_{C_{A n n}}$ is the standard of taste of the assessor at $C_{A n n}$;

(2) Define CAPPUCCINO+ as the proposition featuring in the that-clause of (1)

1 (3) CAPPUCCINO+ has absolute truth-conditions (i.e. it is not assessment-sensitive): CAPPUCCINO+ is true if and only if CAPPUCCINO is true relative to the circumstances $<W_{C_{A n n}}$, $S_{C_{A n n}}>$ where $W_{C_{A n n}}$ is the world of $C_{A n n}$ and $S_{C_{A n n}}$ is the standard of taste of the assessor at $C_{A n n} ;{ }^{25}$

1 (4) CAPPUCCINO+ is a different entity from CAPPUCCINO;

Given scenes 1 and 2, Ann believes CAPPUCCINO because of her personal taste and furthermore she believes CAPPUCCINO+ because she has been persuaded by Linda to believe truth-relativism, hence:

22 However, this new rule of factivity would fail to sanction, by conditional introduction, the truth relative to any standard of assessment $K p \supset p$ which is plausibly an a priori truth.

23 The following is an adaptation of Zimmerman's argument (Zimmerman 2006), Egan raises a similar problem in relation to assertion (Egan 2006).

24 Zimmerman says that such an incomplete semantic entity is something that we cannot "weigh the reasons for and against thinking that it is true" (Zimmerman 2006).

25 This fact should not be given for granted. There are areas of discourse where it is arguable, once truth-relativism is assumed to be the correct semantic theory, that truth-relativism holds also for higher-orders (see in this volume Wright (2008: $\S 4$ ) and Moruzzi and Wright (forthcoming)). 

sidered independently from a context of assessment (i.e. it cannot be entertained as having absolute truth-conditions; analogy with 'I am happy');

1,6 (7) Ann cannot believe CAPPUCCINO, she can only believe CAPPUCCINO+;

\section{1,5,6 (8) Contradiction.}

Thus the conclusion is that CAPPUCCINO fails to have the cognitive role that content should have, i.e. being the object of belief. If the above argument were sound, it would establish the disastrous result that semantics postulates contents which cannot be believed.

Of course the crucial step of the argument is line 6, but why should we assume that the truth-relativity of a proposition must compromise the cognitive role of being object of belief? The obvious problem with this argument is that it assumes, without further argument, that the truth-relativity of a semantic entity forbids that this entity can be the object of a belief with the notable exception of the relativity to possible worlds: only indexical propositions (characters), tensed propositions, and relativist propositions are propositional functions, and thus, being incomplete, they cannot be believed. ${ }^{26}$

In the following section I will offer a better argument for the idea that an assessment-sensitive proposition cannot be the object of belief.

\subsection{FOURTH ATTEMPT}

Remember that the relativization of the accuracy of acceptance of a proposition (e.g. of the correctness of the assertion) does not leave room for the idea that the accuracy of the acceptance and rejection of CAPPUCCINO is absolute. ${ }^{27}$

In the following I will argue that the perspectival notion of accuracy is unsatisfactory because: (1) it fails to explain why, in cases such as Ann's and Mary's dispute over CAPPUCCINO, the parties involved behave as if they really disagree over the truth of the proposition in question-i.e. as if they were genuinely engaged in a dispute; (2) if Mary and Ann believe the truth-relativist story, they are rationally compelled to abstain from disputing over CAPPUCCINO.

26 The style of the argument reminds of Mark Richard's famous argument against temporalism (see Richard 1981).

27 A different notion of accuracy where the context of assessment does not play a role in evaluating the accuracy of a certain acceptance could allow this (see the "use-centric notion of accuracy" in MacFarlane (2007: $\S 4.1)$ ). 
To control the factors involved in the following arguments, I will argue in two phases: first I will consider only Scene 1 of Simple Scenario where it is not assumed that the speakers know the truth-relativist semantics, then I will extend the scenario to Scene 2 where this assumption is in play.

To be clear about the example, let us put aside any possible difference between Ann and Mary in their expertise on the art of cappuccino-making, ${ }^{28}$ and let us suppose also that the application of their standards does not involve, whatever that might mean, an error-i.e. no cognitive shortcoming is involved.

\subsubsection{Argument Limited to Scene 1: A Problem of Explanation}

Let us ask how Ann can recognize Mary's ground for the rejection of CAPPUCCINO. From Ann's perspective, CAPPUCCINO is true and Mary's rejection of CAPPUCCINO is not accurate. ${ }^{29}$ Now, the problem is not that for this latter reason Mary is at fault. After all, if accuracy is perspectival so is the notion of fault. Alternatively, we could also decide to use "fault" just in case the proposition asserted is false relative to the standard of the assertor; in this sense Ann could assert that Mary is not at fault. But this is just a quibble. Rather, the problem arises in connection with the point of the disagreement between Mary and Ann.

According to Relative Assertion 2 (see above $\S 2$ ) acceptance of a proposition involves a commitment to provide a defence if it is challenged from some context of assessment. To what extent can we explain the dispute over CAPPUCCINO on this base? If Mary's challenge to Ann cannot be met in principle unless Ann changes her standard of taste, how can this explain the behaviour of Ann and Mary?

Compare the truth-relativist way of representing the accuracy of Mary's rejection with a situation where Mary has rejected CAPPUCCINO because of a piece of evidence, unknown to everyone except to whom has decided to join her in the rejection. ${ }^{30}$ In such a situation to what extent could Mary challenge Ann's belief about CAPPUCCINO if the only way to show the reasons for her disbelief would be to change her mind? Of course, Mary's challenge might be based on issues accessible also to Ann such as, for example, the fact that the cappuccino is bitter; but while for Mary this would count as a reason for disliking cappuccino, for Ann it would count as the opposite; after such a move they would find themselves in the same situation as before: Mary would say "But don't you feel how it is bitter?!" and Ann would reply "Exactly!" and here the game of giving

28 See contra in this volume Iacona (2008) for the idea that there is no such thing as a dispute involving faultless disagreement when the disputants have the same level of expertise.

29 Given that Ann and Mary's world is the same one and that no further parameter relative to circumstances of use is relevant for the relativist, I omit any reference to circumstances of evaluation in the following.

30 The analogy is derived from a similar example in Rosenkranz (2008). 
and criticizing reasons would have no point, there would simply be nothing more to do. ${ }^{31}$

\subsubsection{First Counter-objection: stalemate is the appropriate prediction}

It could be replied that nothing of what I have said is problematic, in fact this is exactly the kind of stalemate in which disputes of taste typically end. Hence, contrary to my allegations, the relativist predicts exactly what has to be predicted.

Reply: what is problematic is to explain these kind of conversations by means of the idea of challenges and defences: how can the appeal to challenges based on standards which are different from the standards of who is challenged describe such behaviours? What is the point of such challenges if in principle they cannot be met? Wouldn't it be more appropriate to describe these situations just as expressions of our own personal preferences instead of commitments which are in principle right and challenges which are unanswerable?

\subsubsection{Second Counter-objection: controversy just feels uncomfortable}

MacFarlane's reply to the latter questions is that our stubborn attitude to challenge in these extreme circumstances is useful also "to foster coordination of contexts [because we] have an interest in sharing standards of taste [...] with those around us" (MacFarlane (2007), 30). But why is it so? Because, MacFarlane suggests, controversy just feels uncomfortable in itself, and this is just a datum of human nature. ${ }^{32}$

Reply: this move is explanatorily unsatisfactory: the perspectival notion of accuracy (Relative Accuracy) and the idea of characterizing assertion on the basis of a commitment governed by certain rules (Relative Assertion 1 and 2) were meant to provide an explanation of the puzzling phenomenon of faultless disagreement. The advertised advantage of the relativist proposal was that, whereas the hardcore objectivist and the contextualist are at odds in making sense, respectively, of faultlessness and disagreement, the relativist could explain both features. But it turns out now that the relativist package explains this phenomenon only as long as we assume as a brute fact that the behaviour of human agents exhibited in dispute of matters of taste is recalcitrant to any explanation on the basis of the game of asking and giving reasons-i.e. recalcitrant to the relativist's explanans!

\subsubsection{Third Counter-objection: a challenge is an invitation to experiment}

A way to make sense of the idea of challenges and defences in a truth-relativist scenario could be of conceiving a challenge to the assertion of "Cappuccino does not taste good" as an invitation to taste cappuccino in order to get used to its

31 A very similar point is made in Moltmann (forthcoming), $\S 2.2 .1$.

32 MacFarlane refers here to Gibbard (1990) according to whom there is an evolutionary explanation of this fact. 
peculiar flavour in the long run; getting used to cappuccino would thus put you in a position to appreciate it properly. 33

Reply: this interpretation would leave anyway unintelligible a dispute between people who have been tasting cappuccino for a relevantly long period who nonetheless continue to disagree.

\subsubsection{Fourth Counter-objection: disagreement is independent from its manifestation}

It might be protested that the above line of reasoning ties the conditions for the existence of a disagreement with conditions relative to the manifestability of the disagreement: whether or not the point of a dispute is to reach agreement by ratiocinative means (e.g. by means of reasoning or by inspecting the relevant facts), a disagreement requires just the expression of opposite attitudes (i.e. acceptance and rejection) towards a certain proposition. There can be irresolvable disagreements. After all, pace verificationism, we can certainly dispute over unknowable propositions and hence we have cases of irresolvable disputes already. The fact that the conflicting attitudes of Ann and Mary are expression of an irresolvable conflict does not undermine the fact that they are disagreeing; if Ann or Mary change their standards, the dispute can be felicitously solved and there can be convergence of opinions; if they stick to their different standards, they attain to nothing. If the latter happens, the insolubility of the dispute sheds light on the nature of the attitudes involved: they are not beliefs which we are disposed to abandon by ratiocinative means, they are rather tokens of a different type of attitude, e.g. personal preferences, a form of acceptance which is different from, for example, beliefs about the physical properties of the world. ${ }^{34}$

Reply: first, it is suspect to proliferate types of attitudes; how many types of acceptance are there? Can CAPPUCCINO be accepted in different ways in a dispute? If not, how can we describe the case of someone who, after disputing, decides to change her mind? Would she be in error-would she have misunderstood the nature of her own attitude? Or, if she were not in error, what would be the role of the ratiocinative means she has putatively employed in the change of her mind given that this attitude is by definition irresolvable by these means? If, on the other hand, CAPPUCCINO can be accepted in different ways in a dispute, what are the roles of these different attitudes in the dynamic of the dispute? Consider the case of someone believing in creationism for purely religious reasons who is involved in a debate with a biologist who believes, because of a complex scientific enquiry, in evolutionism; there is a sense in which they are talking past each other since the reasons presented by one are, in principle, completely irrelevant

33 I owe this objection to Marco Santambrogio.

34 I have elaborated this objection on the basis of remarks made by Annalisa Coliva. The underlying idea is that acceptance of a proposition can come in different sorts as Wittgenstein already hinted in $O n$ Certainty. 
to the other. If a dispute over CAPPUCCINO can be of this latter sort, in what sense are they disputing given that they appeal to different epistemic norms? Can the very same person change her way of acceptance (e.g. from dogmatist mode of acceptance to non-dogmatist mode) and why and how can it happen? Until these questions are answered the proposal looks rather mysterious.

Second, the case of unknowable propositions is not relevant since what is at stake is not the possibility for the dispute to be solved, rather it is the normative requirement that the disputants should aim to cooperate to solve the problem they are disputing on..$^{35}$

\subsubsection{Conclusion of the argument limited to Scene 1}

In conclusion, it remains a mystery why Mary challenges Ann since any challenge cannot but be won by the challenger and, symmetrically, it is a mystery why Ann asserts CAPPUCCINO since her acceptance is systematically defeated by Mary's challenge. MacFarlane's reply is that this is so because it is a brute fact of human psychology, but I find this reply deeply unsatisfactory.

\subsubsection{Argument Extended to Scene 2: Suspension of Judgement}

Let us put this explanatory problem aside. After all, our doubts could be assuaged by the well-known (and philosophically frustrating) thought that we can't ask for reasons ad infinitum. At a certain point we reach the bedrock. Ann and Mary have simply reached, so to say, their personal bedrock for what counts as a good cappuccino.

Be that as it may, let us move to Scene 2 where Ann and Mary come to believe the truth-relativist story about CAPPUCCINO. I will argue that it is then impossible for the truth-relativist to make sense of the rationality of Ann's and Mary's respective opinions.

Ann and Mary know that acceptance of a proposition involves a commitment to provide a defence if challenged from some context of assessment. To what extent would they dispute about CAPPUCCINO once informed of this fact?

Mary knows that her challenge cannot be met in principle unless Ann changes her standard of taste, and since Ann knows this as well, there is no point in arguing about CAPPUCCINO.

\subsubsection{First Counter-Objection: silence is appropriate}

Again it could be replied that this kind of stalemate is the usual situation in the disputes of taste.

Reply: notice that once we assume knowledge of the truth-relativist doctrine, silence would always be the rational way to act. In fact, if assertion is understood 
in the context of such a dispute as an action undertaking a commitment to face challenges from other perspectives, no challenge can make sense if grounded on a different assessment context, thus the only rational thing to do is to remain silent and not even start disputing. Once Ann and Mary know that there is no point in issuing challenges and replying to them in any other way than persuading the other to stop using her own standard, they would simply cease discussing.

\subsubsection{Second Counter-Objection: truth-relativism does not require rationality}

It might be objected that it is not part of the truth-relativist thesis that speakers have to be rational. ${ }^{36}$

Reply: it is a startling and embarrassing consequence that the truth-relativist analysis of faultless disagreement is at odds with the idea that the disputing behaviour of speakers aware of the semantics of their language is rational.

Moreover notice that if belief, which is a type of acceptance of a proposition, amounts to being prepared to issue and face such challenges, then the fact that Mary and Ann see no point in issuing challenges and replying to them amounts to the fact that they simply would stop believing anything about CAPPUCCINO.

\subsubsection{Conclusion of the argument extended to Scene 2}

In conclusion, Ann and Mary should simply remain silent and unopinionated about CAPPUCCINO. Hence a dispute can take place only insofar as the truthrelativist story is ignored by the speakers. The truth-relativist is committed to an ignorance theory if she does not want to rule out a prori the rationality of disputes of taste. Thus the truth-relativist would fail to part company with contextualist approaches which analyse "It tastes good" as an elliptical expression meaning "It tastes good to me", since also these latter theories are committed to an ignorance theory if they want to save the rationality of a dispute.

\subsection{CONCLUSION}

I have considered four arguments against the idea that assessment-sensitive propositions can represent the right entities that we believe in cases such as controversies in matters of taste. Though the first three arguments have been found to be faulty, they have collectively pointed to an idea developed in the fourth argument. The conclusion of this latter argument is that the truth-relativist story fails to explain why we behave as we actually behave when we are involved in disputes of matters of taste, and that this story entails that we should not 
behave as we actually behave if we were aware of the correct semantics of our language.

Let me close with two final notes. I have chosen the case of disputes of taste since it is a standard case for accounting for the puzzle of faultless disagreement, but I do not think that the points I have made are limited to this area of discourse. Secondly, the arguments presented in the preceding sections are specifically designed against MacFarlane's version of truth-relativism, as it is presently the most developed proposal available. My claim that truth-relativism actually risks losing its advantages over the other positions (mainly contextualism) in respecting the putative idea that there is a real disagreement between opposite parties in matters of taste is thus limited to MacFarlane's theory. However, it may still be the case that other versions of relativism - yet to be developed - would be better off. These other versions could for example develop different notions of acceptance and interplay between the normative rules that govern them. However, the details of these possible developments and changes will have to be investigated and assessed on another occasion. ${ }^{37}$

\section{References}

Baghramian, M. (2004). Relativism, London and New York: Routledge.

Bennigson, T. (1999). 'Is Relativism Self Refuting?', Philosophical Studies 94(3): 211-36. Bilgrami, A. (2002). 'Realism and Relativism', Philosophical Issues 12: 1-25.

Boghossian, P. (2006). Fear of Knowledge, Oxford: Oxford University Press.

Brandom, R. (1994). Making it Explicit, Cambridge, Mass.: Harvard University Press.

Burnyeat, M. (1976a). 'Protagoras and Self-Refutation in Plato's Theaetetus', Philosophical Review 85: 172-95.

(1976b). 'Protagoras and Self-Refutation in Later Greek Philosophy', Philosophical Review 85: 44-69.

Cappelen, H. (2007). 'Content Relativism and Semantic Blindness', this volume.

Davidson, D. (1974). 'On the Very Idea of Conceptual Scheme', Proceedings and Addresses of the American Philosophical Association. repr. in Inquiries into Truth and Interpretation, Oxford: Oxford University Press (1984), 183-98.

Egan, A. (2006). 'Epistemic Modals, Relativism, and Assertion', Philosophical Studies 133(1): $1-22$.

Egan, A., Hawthorne, J. and Weatherson, B. (2004). 'Epistemic Modals in Context', in G. Preyer and G. Peter (eds.), Contextualism in Philosophy, Oxford: Oxford University Press.

37 This paper has hugely benefited from the presentations made in the Arché AHRC Centre for the Philosophy of Logic, Language, Mathematics and Mind in St Andrews and the research seminar on analytic philosophy at the University of Bologna. Special thanks to Eline Busck, Manuel García-Carpintero, Annalisa Coliva, Richard Dietz, Paolo Leonardi, Dan López de Sa, Julien Murzi, Eva Picardi, Marco Santambrogio, and Crispin Wright. 
Evans, G. (1979). 'Does Tense Logic Rest on a Mistake?' in Collected Papers, Oxford: Oxford University Press, 343-63.

Gibbard, A. (1990). Wise Choices, Apt Feelings, Cambridge, Mass.: Harvard University Press.

Hales, S. (1997). 'A Consistent Relativism', Mind 421: 33-52.

Iacona, A. (2008). 'Faultless or Disagreement', this volume.

Kölbel, M. (2002). Truth Without Objectivity, London: Routledge. (2003). 'Faultless Disagreement', Proceedings of the Aristotelian Society 54: 53-73.

Lasersohn, P. (2005). 'Context Dependence, Disagreement, and Predicates of Personal Taste', Linguisticis and Philosophy 28(6): 643-86.

MacFarlane, J. (2003). 'Future Contingents and Relative Truth', The Philosophical Quarterly 53: 321-36.

(2005a). 'The Assessment Sensitivity of Knowledge Attributions', in T. Szabó

Gendler and J. Hawthorne (eds.), Oxford Studies in Epistemology, vol. i, Oxford: Oxford University Press, 197-223.

(2005b). 'Making Sense of Relative Truth', Proceedings of the Aristotelian Society 105: 321-39.

(2007). 'Relativism and Disagreement', Philosophical Studies 132: 17-31.

(forthcoming). 'Semantic Minimalism and Nonindexical Contextualism', in

G. Preyer and G. Peter (eds.), Context-Sensitivity and Semantic Minimalism: Essays on Semantics and Pragmatics, Oxford: Oxford University Press.

Meiland, J. W. (1977). 'Concepts of Relative Truth', The Monist 60: 568-82.

Moltmann, F. (forthcoming). 'First-Person-Oriented Genericity and Relative Truth', Mind.

Moruzzi, S. and Wright, C. (forthcoming). 'Trumping Assessments and the Aristotelian Future', Synthese.

Newton-Smith, W. (1982). 'Relativism and the Possibility of Interpretation', in M. Hollis and S. Lukes (eds), Rationality and Relativism, Oxford: Oxford University Press, 106-22.

Percival, P. (1994). 'Absolute Truth', Proceedings of the Aristotelian Society, 94: 189-213.

Price, H. (2003). 'Truth as Convenient Friction', Journal of Philosophy 100: 167-90.

Richard, M. (1981). 'Temporalism and Eternalism', Philosophical Studies 39(1): 1-13. (2004). Contextualism and Relativism, Philosophical Studies 119: 215-42.

Rosenkranz, S. (2008). 'Frege, Relativism and Faultless Disagreement', this volume.

Siegel, H. (1986). 'Relativism, Truth, and Incoherence', Synthese 68: 225-59.

Stanley, J. (2005). Knowledge and Practical Interests, Oxford: Oxford University Press.

Swoyer, C. (1982). 'True for', in J. Meiland and M. Krausz (eds.), Relativism: Cognitive and Moral, Paris: University of Notre Dame Press.

Wright, C. (2006). 'Intuitionism, Realism, Relativism, and Rhubarb', in P. Greenough and M. Lynch (eds.), Truth and Realism, Oxford: Oxford University Press, 38-70. (2008). 'Relativism about Truth Itself: Further Thoughts about the Very Idea', this volume.

Zimmerman, A. (2006). 'Against Relativism', Philosophical Studies 133(3): 313-48. 